chen und deshalb als er erstere auszog, das vorher melirmals ge-

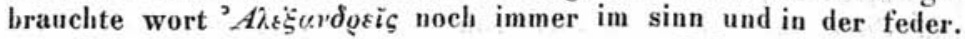
Lüttich. Felix Liebrecht.

\title{
B. Gesehichtliches.
}

\section{Zur chronologie des ersten sicilischen sclaven- krieges.}

Die erste sclaven-empörung auf Sicilien wird noch von Mommsen in der dritten auflage der römischen geschichte bd. 2, p. 78, wie von Peter in der dritten auflage der zeittafeln p. 68 in die jahre 135-132 v. Chr. gesetzt.

Die annahme des ersteren jahres beruht anscheinend auf einer oberflächlichen erwägung der worte des Livius epit. lib. 56: Servile bellum in Sicilia ortum, quum opprimi a praetoribus non potuisset, C. Fulvio consuli mandatum est, indem man schloss, der von den prätoren vergeblich bekämpfte und darum dem C. Fulvius im j. 134 übertragene sicilische krieg habe im j. 135 begonnen, ohne daran zu denken, dass, da ein prätor die insel verwaltete und alljährlich von seinem nachfolger abgelöst wurde, Livius durch den plural a praeloribus dem aufstande eine wenig. stens zweijährige dauer beilegt, bis der consul mit seiner unterdruickung beauftragt wurde.

Diese darstellung des Livius findet ihre bestätigung zunächst durcl Appian. d. bell. civ. lib. 1, c. 9, wo Tib. Gracchus als volks. tribun $\mathrm{im}$ j. 133 unter den motiven für seine lex agraria zò

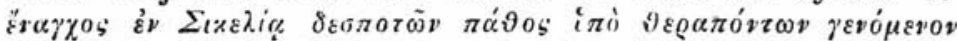

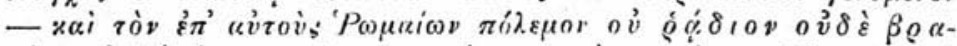

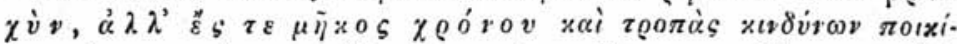
$\lambda \alpha \varsigma \quad \dot{\varepsilon} \times \tau \varrho \alpha \pi \dot{\varepsilon} v \tau \alpha$ anführt: worte, die es wohl unzweifelhaft machen, dass der unselige aufstand im j. 133 schon mehrere jahre gewährt hatte. Ferner erzählt Florus lib. III, c. 19, §. 7 , die entlaufenen sclaven hätten das lager von vier prätoren und zwar das des Manilius, Lentulus, Piso und Hypsaeus erobert. Das würde auf eine wenigstens vierjährige dauer der empörung vor der absendung von consuln hinweisen; man müsste denn an. nehmen, dass die genannten prätoren mindestens theilweise der zeit angehörten, wo consuln auf der insel kommandirten, was mir aus zwei gründen unzulässig erscheint, denn von 134 an ging es mit dem aufstande überhaupt rückwärts, und dann war die niederlage eines prätors jedenfalls unerheblich, wenṇ die waffen des höchstkommandirenden consuls erfolg hatten.

Zu den genannten vier prätoren kommt nun noch ein fünfter, der zwar unter dem schleier der anonymität versteckt, aber von Mommsen mit dem ihm eigenen scharfsinn als der consul des 
j. 132, P. Popillius Latenas, entlarvte prätor, der in der insehrift von Polla Inser. Lat. n. 551 von sich sagt: praelor in Sicilia fugiteivos l'alicorum conquaeisivei redideique homines DCCCCXVII. Die verwaltung des Laenas fiel, wie Mommsen schlagend dargethan hat, in die zeit kurz vor ausbruch des förmlichen krieges, wo derselbe aber durch, räuberbanden schon vorbereitet wurde.

Nach Diodor exc. lib. XXXIV, tom. IV, p. 137, 19 ed. Teulner.

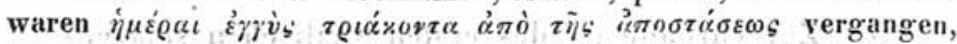
als sich die beiden chefs des aufstandes Eunus und Kleon ver. banden und ihre haufen dadurch auf 11,000 mann brachten; bald

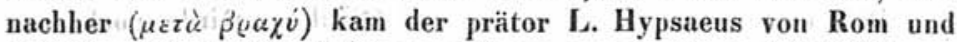
lieferte mit 8000 sicilischen milizen gegen die auf 20,000 gestiegenen sclaven eine schlacht, in der er erlag. Diod. z. 2022. Da hiernach der eigentliche ausbruch des krieges in das verwaltungsjahr des Hypsaeus fällt, so werden wir die prätur des Laenas ohne bedenken in das jahr vorher setzen.

Bei Florus ist Hypsaeus als der letzte derjenigen prätoren quorum castra capte sunt anfgeführt: da nun unter ihm der eigentliche krieg ausbrach, dürfte es nicht unwahrscheinlich sein, dass Florus die vier geschlagenen statthalter in umgekehrter chronologischer ordnung aufgezählt hat. Demnach wäre denn die prätur

$\begin{array}{llll}\text { des Manilius ins jahr } & 135 \\ \text { des Lentulus , } & , & 136 \\ \text { des Piso ", } & 137 \\ \text { des Hypsaeus , , } & 138\end{array}$

und die des Popillius Laenas , , 139 zu sefzen.

Das bisher ausgeführte findet endlich eine nicht unerhebliche bestätigung in den schon bei Fischer Roem. Zeittafeln angeführten, aber wunderbarer weise wenig beachteten worten Diodors

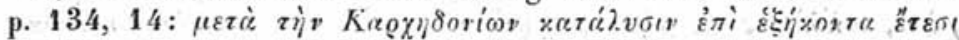

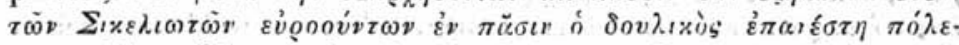
uos. Die auflösung der karthagischen macht war offenbar mit dem frieden v. j. 201 eingetreten: gegen 60 jalıre später, d. h. um 140, fand die sicilische sclavenerhebung statt. Dieselbe kanu jedoch füglich noch ein oder zwei jahre vor dem oben angenommenen j. 138 zum förmlichen kriege umgewandelt sein, denn das gegebene prätoren-verzeichniss braucht kein vollständiges zu sein, da die reihe derjenigen, quorum castra capta sunt, ja durch solche unterbrochen gewesen sein kann, denen dies nicht widerfuhr, und die Florus daher bei aufzählung der ersteren unerwähnt lassen musste.

Der sclaven-aufstand auf Sicilien hat also nicht 135 , son, dern wenigstens 139 , vielleicht sogar schon 140 oder 141 begonnen; er ist im nächsten jahre zum förmlichen kriege geworden, den wenigstens vier prätoren vergebens zu dämpfen versuchten; erst als seit 134 alljährlich einer der beiden consuln mit der 
führung dieses krieges beauftragt wurte, gelang die beendigung desselben im j. 132.

Neustettin.

W. Lehmann.

\section{Auszäge aus schriften und berichten der gelehrten gesellschaften sowie aus zeitschriften.}

The Edinburgh Review, nr. CCXI, V, juli, 1864: De Ros$s i$ 's Christiun and Jenish Inscriptions (zusammen mit Le Blant, Inscriptions de la Gaule antérieures au VIII'siècle und mit den auf denselben gegenstand bezüglichen schriften von Garucci und Seognamiglio). Der artikel (vrgl. Philol. XXI, p. 373) giebt zuerst eine geschichte der christlichen epigraphik. Alsdann sucht der verfasser gegen Rossi zu zeigen, dass das monogramm $\mathbb{R}$ nicht vor Constantiu gebraucht worden sei. Die inscriptionen I ce Blant's - die meisten aus Tours, Lyon und Trier - fangen erst mit 334 n. Clir. an. Sie sind, bis auf eine griechische inschrift aus Autun (ein akrostichon in hexametern), lateinisch, mit wenigen spuren des einflusses des griechischen, während die inschriften aus den römischen katakomben, ein stärkeres griechisches element aufweisen, uuch in den inflexionen der wörter. In den letzteren zeigt die orthographie öfter einen auffallenden übergang in die jetzige italiänische. In beiden werken sind die inschriften auf christliche soldaten selten, indem die profanen die soldaten in zehnmal höherem verhältniss aufzeigen. Es werden einige inschriften mitgetheilt. Endlich wird nachricht von den bei Rom entdeckten hebräischen kirchhöfen gegeben. In Le Blant's sammlung sind auch einige Runen-inschriften. P, 217-248. - Nr. CCXLVI, oct. 1864 enthält nichts philologisches. - $\mathrm{Nr}$. CCXLVII, januar, 1865: Homers iliade übersetzt in dem englischen ,hlank verse". (reimlose fünffüssige jamben) von e arl Derby, Der berichterstatter, welcher im eingang eine ausserordentlich gelungene übersetzung des lords von Catull. e. XXXI, abdrucken lässt, behauptet dass das studium des alterthums in England nicht in verfall gerathen sei, beachte man nur, dass staatsmänner wie Sir George Lewis, Gladstone und earl Derby zugleich hervorragende vertreter der klassischen gelehrsamkeit wären. Auf jeden fall hat hierin der engländer recht $\mathrm{zu}$ einem wohlbegründeten stolz: in Deutschland haben wir etwas ähnliches nicht aufzuweisen. Der verfasser des aufsatzes lobt die übersetzung als anziehend und fliessend, und stellt sie in dieser beziehung über die Pope's und Cowper's wenngleich er diesen beiden in der sorg. fältigen versification den vorzug giebt. Er theilt einige proben mit, welche, so geschmackvoll sie auch geschrieben sind, nach unserm urtheil, die mannichfaltigkeit des tons und die erhaben- 